І. П. Саланда ${ }^{1}$, Н. В. Бабій ${ }^{1}$, О. А. Фурман ${ }^{1}$, Ю. Є. Мельничук ${ }^{2}$

${ }^{1}$ Кременецька обласна гуманітарно-педагогічна академія, Кременець, Україна

2 Луцький національний технічний університет, Луцьк, Україна

\title{
МЕТОДИКА СИНТЕЗУ ГЕТЕРОГЕННИХ ІНФОРМАЦІЙНИХ МЕРЕЖ НА ОСНОВІ ВВЕДЕННЯ КОРИГУВАЛЬНИХ ЦИКЛІВ
}

\begin{abstract}
Анотац ц я . В роботі поставлено завдання синтезу структури гетерогенної інформаційної мережі за критерієм максимуму показника функціональної стійкості при обмеженнях на вартість проектування і експлуатації мережі. В якості показника функціональної стійкості вибрано ймовірність зв'язності мережі. Дане завдання є складним при нерівнонадійних ребрах, однак у випадку рівнонадійних ребер знайдено точні спільні рішення для деяких класів графів і спільні властивості оптимальних структур в цілому. Така постановка завдання в практичному розумінні інтерпретується як намагання отримати структуру мережі, яка б за рахунок закладеної надмірності могла б максимально чинити опір зовнішнім та внутрішнім дестабілізуючим факторам. Основна увага надається оптимальнозв'язним циклічним структурам, тобто структурам, що містить чітко виражені цикли. Розглядається питання оптимального додавання коригувальних циклів до циклічних графів з метою підвищення їх ймовірності зв'язності. Доведено оптимальність розбиття з'єднуваних циклів на ланцюги рівної (з точністю до одиниці) дожини. В процесі дослідження розроблено методику синтезу гетерогенної інформаційної мережі на основі введення коригувальних циклів. Вказана методика дозволяє забезпечувати виконання основної функції мережі протягом заданого проміжку часу в момент перебудови активної структури. Це дозволяє відновити працездатність програмних компонент в умовах гетерогенних комп'ютерних ресурсів. Вартість капіталовкладень на побудову та експлуатацію мережі може бути обрана проектувальником на будь-якому рівні, що не перевищує виділених обсягів інвестицій. В результаті математичного моделювання отримано графіки поліномів зв'язності гетерогенних мереж, які підтверджують справедливість розробленої методики синтезу гетерогенних інформаційних мереж на основі введення коригувальних циклів.
\end{abstract}

Кл юч ов і слов а : інформаційна мережа, зв'язність, методи оптимізації, надмірність, гіпермережа, функціональна стійкість.

\section{ВстуII}

Головною вимогою до інформаційних гетерогенних мереж $\epsilon$ виконання мережею іiі основної функції - забезпечення абонентів мережі потенційною можливістю доступу до розподілених інформаційних ресурсів. Всі інші вимоги пов'язані з якістю виконання цього основного завдання. У цьому плані особливий інтерес становить побудова функціонально-стійких мереж, які дозволяють вирішувати поставлені завдання під впливом дестабілізуючих факторів [1, 2]. Реалізація функціональної стійкості досягається застосуванням в складній технічній системі різних уже існуючих видів надмірності (структурної, часової, інформаційної, функціональної та ін.) шляхом перерозподілу ресурсів з метою парирування наслідків позаштатних ситуацій.

Завдання синтезу оптимальних структур гіпермереж допускають застосування традиційних оптимізаційних методів: лінійного і динамічного програмування [3, 4]. Оскільки ці методи погано враховують структурні особливості виникаючих завдань, в більшості випадків вони виявляються недостатньо ефективними, і тому в даній роботі не розглядаються, а основна увага приділяється методам теорії графів і споріднених дисциплін $[5,6]$.

\section{Аналіз публікацій}

Підвищення ефективності функціонування інформаційних мереж $є$ важливим науковим завданням. Вирішенню цього завдання присвячено багато наукових робіт. Однак, на наш погляд, основна увага в них приділяється вирішенню часткових завдань, a саме - побудови резервованих інформаційно- керуючих мереж [7- 9], відмовостійких обчислювальних мереж [10, 11], адаптивних систем управління $[12,13]$, оптимізації пропускних здатностей каналів зв' язку [14-16].

Існуючі методи оптимізації мереж, які базуються на підвищенні зв'язності гіпермережі за рахунок розпаралелювання ребер вторинної мережі не завжди виявляються придатними, так як структура вторинної мережі залишається незмінною.

Тому в даній роботі поставлено завдання синтезу структури PIM за критерієм максимуму показника функціональної стійкості при обмеженнях на вартість проектування і експлуатації мережі:

$$
\begin{aligned}
& f\left(P_{\text {зв. }}\right) \rightarrow \max \\
& \varphi(S) \leq \varphi_{\text {зад. }}(S),
\end{aligned}
$$

де $P_{\text {зв. }}$ - ймовірність зв'язності мережі, $\varphi(S)$ - вартість проектування та експлуатації мережі $S$ [17].

Дана постановка відповідає логіці побудови мереж спеціального призначення, відповідає сучасним умовам і носить однокритеріальний характер, що дозволяє досягти потрібного результату. Результатом вирішення даного завдання буде множина ліній зв'язку між вузлами комутації гетерогенної інформаційної мережі.

Метою статті $\epsilon$ розробка методу синтезу оптимальної структури інформаційної мережі за критерієм максимуму функціональної стійкості, що базується на введені коригувальних циклів.

\section{Основна частина}

Розглянемо питання оптимального з'єднання незалежних циклів в граф більшої розмірності: потрібно так з'єднати цикли коригувальними циклами, 
щоб результуючий граф був циклом та оптимальнозв'язним.

Нехай маємо $k$ циклів довжини $n_{1}, n_{2}, \ldots, n_{k}$, з'єднаних коригувальним циклом таким чином, що існує єдине ребро, яке з'єднує перший цикл з другим, єдине ребро, що з'єднує другий цикл з третім і так далі, і єдине ребро, яке з'єднує $k$-й цикл $з$ першим (рис. 1). Дослідимо питання оптимального способу розташування ребер, що входять в коригувальний цикл.

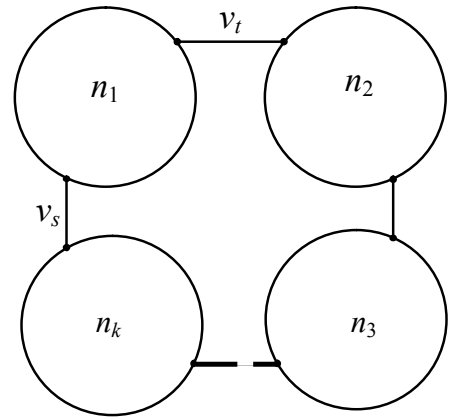

Рис. 1. Введення коригувального циклу при зв'язуванні структури $k$ циклів

Виберемо довільний цикл із з'єднуваних. Для зручності опустимо індекси: нехай довжина його дорівнює $n$ і вершини, інцидентні ребрам коригувального циклу, позначимо $v_{s}$ i $v_{t}$, ділять цикл на ланцюги довжиною $w$ i $u=n-w$.

Скористаємося методом послідовно-паралельної редукції. Ребро, яке відповідає ланцюгу довжини $w$ буде, матиме ймовірність наявності

$$
p_{1}=\frac{1}{w / p-w+1}=\frac{p}{w-(w-1) p},
$$

а ребро, відповідне ланцюгу довжини $u$, буде мати ймовірність наявності

$$
p_{2}=\frac{p}{u-(u-1) p}=\frac{p}{n-w-(n-w-1) p} .
$$

Далі замінюємо пару одержані кратних ребер еквівалентним ребром з ймовірністю

$$
\begin{gathered}
p^{*}=p_{1}+p_{2}-p_{1} \cdot p_{2}=\frac{p}{w-(w-1) p}+ \\
+\frac{p}{n-w-(n-w-1) p}-\frac{p}{w-(w-1) p} \times \\
\quad \times \frac{p}{n-w-(n-w-1) p}= \\
=\frac{n p-(n-1) p^{2}}{[w-(w-1) p][n-w-(n-w-1) p]} .
\end{gathered}
$$

Отриманий граф позначимо як $H$, а отримане ребро - $e_{s t}$. При цьому величина коефіцієнта, на який потрібно помножити ймовірність зв'язності отриманого графа для отримання ймовірності зв’язності вихідного, дорівнює

$$
\begin{aligned}
& r=p^{w}\left(\frac{w}{p}-w+1\right) \cdot p^{n-w}\left(\frac{n-w}{p}-n+w+1\right)= \\
& =p^{n-2}[w-(w-1) p][n-w-(n-w-1) p] .
\end{aligned}
$$

Далі проведемо крок розгалуження за формулою Мура-Шеннона по цьому ребру, як показано на рис. 2 отримаємо

$$
\begin{gathered}
P_{36 .}(G)=r P_{36 .}(H)= \\
=r p^{*} P_{36 .}\left(H^{*}\left(e_{s t}\right)\right)+r\left(1-p^{*}\right) P_{36 .}\left(H \backslash\left\{e_{s t}\right\}\right) .
\end{gathered}
$$

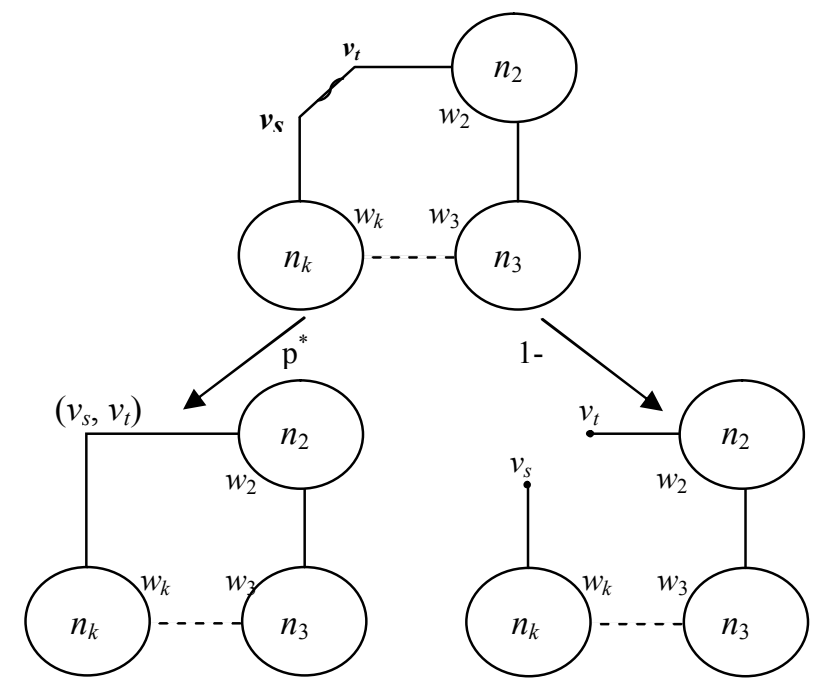

Рис. 2. Розгалуження по ребру $e_{s t}$

Графи $H^{*}\left(e_{s t}\right)$ і $H \backslash\left\{e_{s t}\right\}$, отримані в результаті розгалуження, не залежать від розбиття розглянутого циклу на ланцюги. Порівняємо ймовірності зв'язності, отримані в останній рівності для випадку ділення циклу навпіл і на різні частини.

Позначимо відповідні ймовірності наявності дозвільного ребра і коефіцієнти як $p^{*}$ i $r^{*}$, i $p^{\prime}$ i $r^{\prime}$, відповідно. Для стислості позначимо $P_{3 в .}\left(H^{*}\left(e_{s t}\right)\right)$ як $A$ i $\left(H \backslash\left\{e_{s t}\right\}\right)$ як $B$.

Маємо різницю

$$
\begin{aligned}
& P^{*}(G)-P^{\prime}(G)=r^{*} p^{*} A+r^{*}\left(1-p^{*}\right) B-r^{\prime} p^{\prime} A- \\
& -r^{\prime}\left(1-p^{\prime}\right) B=\left(r^{*} p^{*}-r^{\prime} p^{\prime}\right)(A-B)+\left(r^{*}-r^{\prime}\right) B .
\end{aligned}
$$


Неважко бачити, що добуток коефіцієнта на ймовірність наявності дозвільного ребра $\left(r \cdot p^{*}\right)$ в нашому випадку завжди дорівнює $n p^{n-1}-(n-1) p^{n}$, тому перший доданок в попередній рівності завжди дорівнює нулю. Відповідно, знак визначається другим доданком, тобто достатньо розглядати значення коефіцієнтів. Маємо два випадки: парну і непарну довжини циклу.

1) $n=2 k$. У передбачуваному оптимальному випадку $w=n-w=k$. Для порівняння беремо $w=k-d, 1<d<k .3(*)$ отримаємо:

$$
\begin{gathered}
r^{*}=p^{n-2}(k-k p+p)(k-k p+p)= \\
=p^{n-2}(k-k p+p)^{2} ; \\
r^{\prime}=p^{n-2} \times \\
\times(k+d-k p-d p+p)(k-d-k p+d p+p)= \\
=p^{n-2}\left((k-k p+p)^{2}-(d-d p)^{2}\right) .
\end{gathered}
$$

Різниця складає

$$
\begin{gathered}
\delta=p^{n-2}(k-k p+p)^{2}-p^{n-2} \times \\
\times\left((k-k p+p)^{2}+(d-d p)^{2}\right)= \\
=p^{n-2}(d-d p)^{2}>0 .
\end{gathered}
$$

2) $n=2 k+1$. В передбачуваному оптимальному випадку $w=k, n-w=k+1$. Для порівняння візьмемо $w=k+d, 2 \leq d<k$.

3 (1) отримаємо наступні значення коефіцієнтів:

$$
\begin{gathered}
r^{*}=p^{n-2}(k-k p+p)(k+1-k p)= \\
=p^{n-2}\left[(k-k p+p)^{2}+(k-k p+p)(1-p)\right] \\
r^{\prime}=p^{n-2}(k+d-k p-d p+p)(k+1-d-k p+d p)= \\
=p^{n-2}[(k-k p+p)+(d-d p)][(k-k p+p)- \\
-(d-d p)+1-p] .
\end{gathered}
$$

Різниця складає

$$
\begin{gathered}
\delta=p^{n-2}\left[(k-k p+p)^{2}+(k-k p+p)(1-p)\right]- \\
-p^{n-2}[(k-k p+p)+(d-d p)][(k-k p+p)- \\
-(d-d p)+1-p]=p^{n-2} d(1-p)^{2}(d-1)>0 .
\end{gathered}
$$

Застосовуючи ці міркування до всіх з'єднуваних циклів приходимо до висновку, що ймовірність зв'язності графа, який складається із з'єднання циклів єдиними ребрами коригувального циклу максимальна, коли вершини, інцидентні з'єднуваним ребрам, ділять цикли на ланцюги, довжина яких відрізняється не більше ніж на одиницю.

\section{Методика синтезу структури гетерогенної інформаційної мережі шляхом введення коригувальних циклів для підвищення функціональної стійкості структури}

При оптимальному з'єднанні $k$ незалежних циклів в граф більшої розмірності, потрібно так з'єднати цикли коригувальним циклом заданої довжини, щоб результуючий граф був максимально зв'язним, тобто задовольняв критерію максимуму функціональної стійкості. завдання:

Для цього необхідно послідовно вирішити такі

1. Вивести залежність $P_{\text {зв. }}(p)$ - ймовірності зв'язності для вихідної структури.

2. Визначити вершини, які будуть інцидентні ребрам коригувального циклу. Визначити структурні параметри цих вершин $-w_{i}$ та $u_{i}$ - довжини ланцюгів, на які вказані вершини ділять $i$-тий зв’ язувальний цикл.

3. Застосовуючи редукцію ланцюгів та формулу Мура-Шеннона визначити залежність $P_{3 в .}(p)$ для отриманої структури.

4. Визначити при яких значеннях $w_{i}$ та $u_{i}$ буде максимальний приріст ймовірності зв'язності. Для цього необхідно поділити $k$ з'єднувальних цикли на ланцюги, довжини яких відрізняються не більше ніж на одиницю.

5. Визначити значення показника $P_{\max }(p)$, що $\epsilon$ найбільшим для введеного коригувального циклу.

6. Ввести коригувальний цикл між знайденими вершинами 3 параметрами $w_{i}$ та $u_{i}, i=1, \ldots, k$, які $\epsilon$ оптимальними.

7. Зробити висновки про доцільність введення коригувального циклу.

Опис результатів, отриманих при проведенні імітаційного моделювання. В якості прикладу розглянемо приклад (рис. 3), який показує справедливість висновків про оптимальне з'єднання $k$ кільцевих гетерогенних мереж коригувальним циклом 3 $k$ коригувальними ребрами таким чином, щоб кінці цих ребер ділили з'єднані цикли навпіл.

Поліноми, що відповідають наведеним на рис. 3 варіантам з'єднання коригувальними циклами, мають вигляд:

$$
\begin{aligned}
P_{a}(p)= & p^{21}+21(1-p) p^{20}+189(1-p)^{2} p^{19}+ \\
& +864(1-p)^{3} p^{18}+1620(1-p)^{4} p^{17}, \\
P_{6}(p)= & p^{21}+21(1-p) p^{20}+188(1-p)^{2} p^{19}+ \\
& +852(1-p)^{3} p^{18}+1584(1-p)^{4} p^{17}, \\
P_{6}(p)= & p^{21}+21(1-p) p^{20}+177(1-p)^{2} p^{19}+ \\
& +720(1-p)^{3} p^{18}+1188(1-p)^{4} p^{17}, \\
P_{2}(p)= & p^{21}+21(1-p) p^{20}+162(1-p)^{2} p^{19}+ \\
& +540(1-p)^{3} p^{18}+648(1-p)^{4} p^{17} .
\end{aligned}
$$

На рис. 4 наведені графіки полінома зв'язності для оптимального (варіант а) і найгіршого (варіант г) випадків введення коригувальних циклів.

Максимальна різниця, що дорівнює 0.1072, досягається в точці

$$
p=0.851 \text {. }
$$

Таким чином, експериментально досліджена справедливість розробленої методики синтезу гетерогенних інформаційних мереж на основі введення коригувальних циклів. 

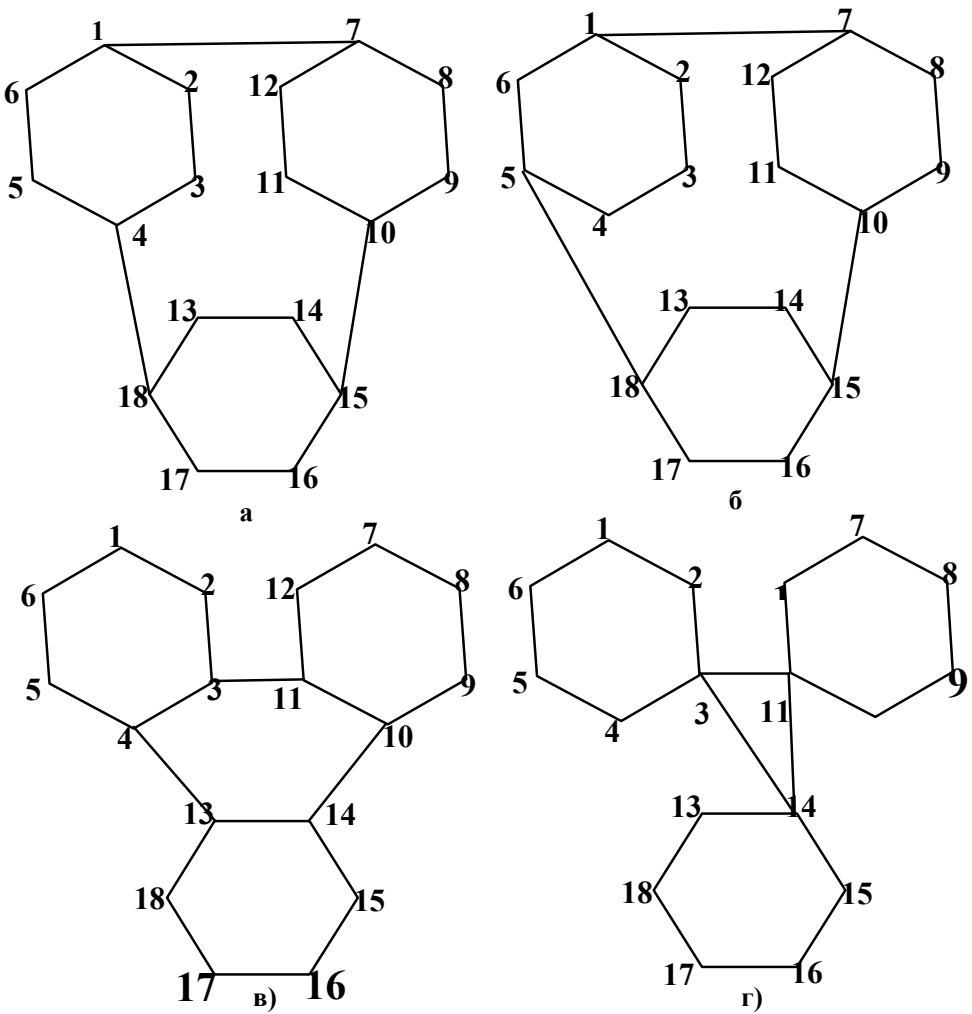

Рис. 3. Приклад з’єднання кільцевих гетерогенних мереж коригувальним циклом

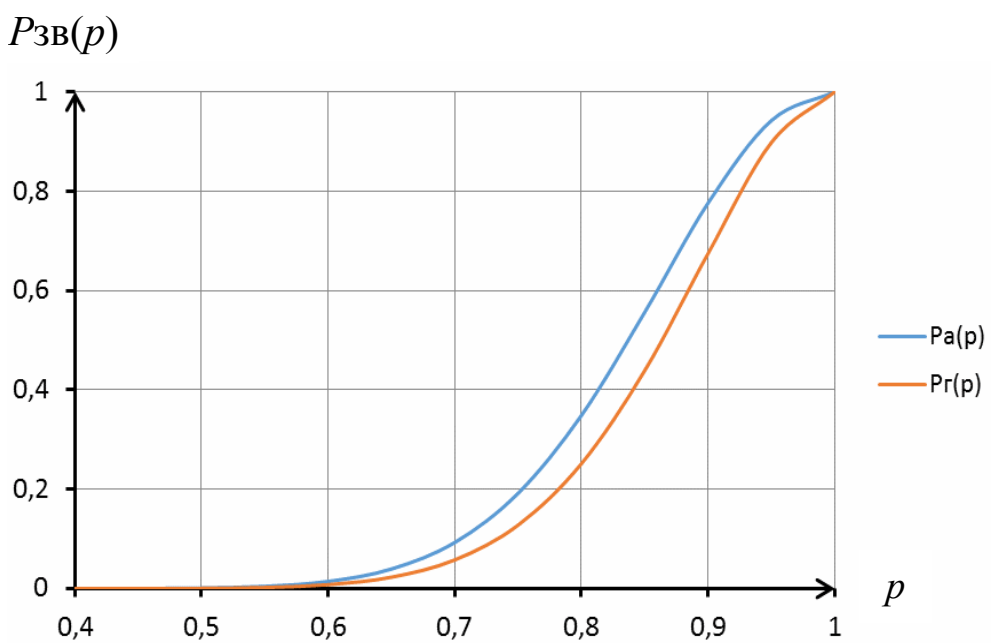

Рис. 4. Графіки поліномів зв’язності гетерогенних мереж а) та г) з рис. 3

\section{Висновки}

В роботі досліджено існуючі методи синтезу розгалужених інформаційних мереж шляхом введення коригувальних зв'язків та їх вплив на функціональну стійкість структури мережі. В результаті проведених досліджень вперше розроблено метод синтезу структури гетерогенної інформаційної мережі на основі введення коригувальних циклів. Да- ний метод полягає в поділі циклічних мереж коригувальним циклом на ланцюги, довжини яких відрізняються не більше ніж на одиницю. В якості критерію оптимізації вибраний максимум функціональної стійкості мережі. Виходячи з особливостей парирування відмов і пошкоджень функціонально стійкими мережами, як показник функціональної стійкості обгрунтовано вибрана ймовірність зв'язності $P_{\text {зв. }}(S)$ графа структури мережі.

\section{СПИСОК ЛІТЕРАТУРИ}

1. Саланда І.П., Барабаш О.В., Мусієнко А.П. Система показників та критеріїв формалізації процесів забезпечення локальної функціональної стійкості розгалужених інформаційних мереж. Наукове періодичне видання «Системи управління, навігації та зв'язку». Полтава: ПНТУ, 2017. Вип. 1 (41). С. 122 - 126. 
2. Sobchuk A.V., Sobchuk V.V., Barabash O.V., Liashenko I.O. Functionally sustainable wireless sensor network technologies aspects analysis. Science and Education a New Dimension. Natural and Technical Sciences, 2019, No VII (23), Issue 193, p. $46-48$.

3. Schneider, C., Barker, A., and Dobson, S. (2015) "A survey of self $\square$ healing systems frameworks." Software: Practice and Experience, 45(10): 1375-1398. Print.

4. Собчук В.В., Кучук Н.Г., Гавриленко С.Ю., Лукова-Чуйко Н.В. Перерозподіл інформаційних потоків у гіперконвергентній системі. Науково-технічний журнал «Сучасні інформаційні системи». Харків: НТУ «Харківський політехнічний інститут», 2019. Т. 3, № 2. С. $116-121$.

5. Manzoor A., Rajput U, Phulpoto N, Abbas F, Rajput M. (2018) "Self-healing in Operating Systems." IJCSNS International Journal of Computer Science and Network Security, Vol.18 No.5: 92-98. Print.

6. Саланда І.П., Барабаш О.В., Мусієнко А.П., Лукова-Чуйко Н.В. Математична модель структури розгалуженої інфораційної мережі 5 покоління (5G) на основі випадкових графів. Наукове періодичне видання «Системи управління, навігації та зв'язку». Полтава: ПНТУ, 2017. Вип. 6 (46). С. 118 - 121.

7. Hudaib, AA., Fakhouri, HN., Al Adwan, FE., and Fakhouri, SN. (2017) “A Survey about Self-Healing Systems” (Desktop and Web Application). Vol.09 No.01: 71-88. Print.

8. Машков О.А., Косенко В.Р. Синтез функціонально-стійкої системи керування рухомим об'єктом із заданими динамічними властивостями. Збірник наукових праць, Інститут проблем моделювання в енергетиці НАН України, Київ, ІПМЕ НАН України, 2011. Вип. 60. С. 186 - 214.

9. Одарущенко О.М. Оцінювання та забезпечення функційної безпеки при розробленні та ліцензуванні модулів і платформ для програмно-технічних комплексів інформаційно-керуючих систем. Наукове періодичне видання «Системи управління, навігації та зв'язку». Полтава: ПНТУ, 2020. Вип. 3 (61). С. 90 - 93.

10. Wang, Z., \& Wang, J. (2015) "Self-healing resilient distribution systems based on sectionalization into microgrids." IEEE Transactions on Power Systems, 30(6): 3139-3149 Print

11. Sobchuk A.V., Barabash O.V., Musienko A.P. Assessment methods of functional stability of wireless sensor networks. Hayковий журнал «Телекомунікаційні та інформаційні технології». Київ, ДУТ, 2019. № 3 (64). С. 46 - 54.

12. Duarte, DP., Guaraldo, JC., Kagan, H., Nakata, BH., Pranskevicius, PC., Suematsu, AK., and Hoshina, MS. (2016) "Substation-based self-healing system with advanced features for control and monitoring of distribution systems." In Harmonics and Quality of Power (ICHQP), 2016 17th International Conference on 2016, IEEE: 301-305. Print.

13. Собчук В.В., Мусієнко А.П., Ільїн О.Ю. Аналіз використання ієрархічної структури для забезпечення функціональної стійкості автоматизованої системи управління підприємством. Науковий журнал «Телекомунікаційні та інформаційні технології». К.: ДУТ, 2018. № 4 (61). С. 53 - 61.

14. Собчук В.В., Кучук Н.Г., Лукова-Чуйко Н.В. Оптимізація пропускних здатностей каналів зв'язку гіперконвективної системи. Наукове періодичне видання «Системи управління, навігації та зв'язку». Полтава: ПНТУ, 2019. Вип. 3 (55). C. $120-125$.

15. Mozhaiev M., Kuchuk N., Usatenko M. The method of jitter determining in the telecommunication network of a computer system on a special software platform. Innovative technologies and scientific solutions for industries, 2019. Vol. 4 (10), pp. 134-140. doi: https://doi.org/10.30837/2522-9818.2019.10.134

16. Свиридов А. С., Коваленко А. А., Кучук Г. А. Метод перерозподілу пропускної здатності критичної ділянки мережі на основі удосконалення ON/OFF-моделі трафіку. Сучасні інформаційні системи. 2018. Т. 2, № 2. C. 139-144. DOI: https://doi.org/10.20998/2522-9052.2018.2.24

17. Скулиш М.А., Вольвач С.О., Глоба Л.С. Система керування якістю обслуговування у складних гетерогенних телекомунікаційних системах. Наукове періодичне видання «Системи управління, навігації та зв'язку». Полтава: ПНТУ, 2017. Вип. 6 (46). С. $158-162$.

Received (Надійшла) 22.09.2020

Accepted for publication (Прийнята до друку) 28.10.2020

\section{Methods of synthesis of heterogeneous information networks based on the introduction of adjustment cycles}

I. Salanda, N. Babiy, O. Furman, Yu. Melnychuk

Abstract. The paper sets the task of synthesizing the structure of a heterogeneous information network by the criterion of the maximum of the indicator of functional stability with restrictions on the cost of network design and operation. The probability of network connectivity is chosen as an indicator of functional stability. This problem is difficult for unequally reliable edges, but in the case of equally reliable edges, exact common solutions for some classes of graphs and common properties of optimal structures as a whole are found. Such a problem statement in the practical sense is interpreted as an attempt to obtain a network structure that would, due to the underlying redundancy, could maximally resist external and internal destabilizing factors. The main attention is paid to optimally connected cyclic structures, that is structures containing clearly expressed cycles. The question of optimal addition of correction cycles to cyclic graphs in order to increase their probability of connectivity is considered. The optimality of dividing the connected cycles into chains of equal (to the nearest one) length is proved. In the course of research, the technique of synthesis of a heterogeneous information network on the basis of introduction of corrective cycles is developed. This technique allows you to perform the main function of the network for a specified period of time at the time of restructuring the active structure. This allows you to restore the functionality of software components in terms of heterogeneous computer resources. The cost of investment in the construction and operation of the network can be selected by the designer at any level that does not exceed the allocated amount of investment. As a result of mathematical modeling, graphs of polynomials of connectivity of heterogeneous networks are obtained, which confirm the validity of the developed method of synthesis of heterogeneous information networks based on the introduction of correction cycles.

Keywords: information network, connectivity, optimization methods, redundancy, hypernetwork, functional stability. 